\title{
MODULAÇÃO DAS RESPOSTAS INFLAMATÓRIAS DE CÉLULAS INTESTINAIS HUMANAS POR EXTRATO DE FOLHA DE PASSIFLORA EDULIS
}

\author{
Ana Elisa R. Magalhães*, Mônica C. L. do Carmo, Juliana A. Macedo.
}

\section{Resumo}

Atualmente o tratamento das Doenças Inflamatórias Intestinais (DII) envolve uso de fármacos que geram graves efeitos colaterais. O presente estudo avalia um tratamento alternativo, em que os antioxidantes presentes no extrato da folha de Passiflora edulis têm papel chave no controle do processo inflamatório de células epiteliais intestinais. Os resultados apontam que o extrato possui potencial terapêutico, contribui na recuperação da integridade das células e reduz os estímulos inflamatórios.

Palavras-chave: Passiflora edulis, doença inflamatória intestinal, potencial anti-inflamatório.

\section{Introdução}

O trato gastrointestinal possui um sistema natural de defesa compreendido por um sistema imune, presença de muco, microbiota comensal e uma monocamada de células epiteliais, unidas por junções intercelulares, que possuem características seletivas de permeabilidade (Cazarin et al., 2015; Podolsky, 2002).

As DII estão relacionadas ao funcionamento defeituoso da barreira celular epitelial e a uma atividade imune exagerada, resultando na liberação de estímulos e citocinas pró-inflamatórias e no aumento da permeabilidade das membranas. Sua etiologia ainda não é bem elucidada e o tratamento envolve uso de fármacos que geram graves efeitos colaterais, têm alto custo e não são eficientes no controle do processo inflamatório. Devido a isso, outras formas de tratamentos são focos de estudos, destacando-se os alimentos antioxidantes. A Passiflora edulis (maracujá azedo ou amarelo) é rica em compostos fenólicos, considerados antioxidantes naturais, além de ser uma planta nativa e facilmente encontrada no mercado (Cazarin et al., 2015).

O objetivo do trabalho foi avaliar a capacidade de um extrato da folha de Passiflora edulis em reduzir os mediadores inflamatórios gerados por uma monocamada de células epiteliais humanas (Caco-2) e células de macrófagos (RAW 264.7) num estudo in vitro simulando um processo inflamatório.

\section{Resultados e Discussão}

Avaliou-se o comportamento de uma monocamada de células epiteliais humanas (Caco-2) via medição da resistência elétrica transepitelial (TER). A TER é usada para o controle da uniformidade da membrana e de suas junções intercelulares. Após atingirem TER $>400 \Omega \times \mathrm{cm}^{2}$ (equivalente a $100 \%$ de integridade), as membranas receberam estímulo inflamatório (LPS $10 \mu \mathrm{g} / \mathrm{mL}+\mathrm{IL} 1-\beta$ $10 \mathrm{ng} / \mathrm{mL}$ ) e posterior tratamento com extrato da folha de $P$. edulis nas concentrações de 10 e $5 \mathrm{mg} / \mathrm{mL}$. Outras membranas receberam apenas o tratamento com extrato para avaliação de propriedades terapêuticas (Tabela 1).

Tabela 1. Percentual de TER para monocamada.

\begin{tabular}{|l|c|c|c|}
\hline \multirow{2}{*}{ Tratamento } & \multicolumn{3}{|c|}{ TER (\%) } \\
\cline { 2 - 4 } & Inicial & $\begin{array}{c}\text { Após 6h de } \\
\text { inflamação }\end{array}$ & $\begin{array}{c}\text { Após 45h de } \\
\text { Extrato }\end{array}$ \\
\hline Infl + Ext 10 & 100 & 76 & 132 \\
\hline Infl+ Ext 5 & 100 & 75 & 103 \\
\hline Ext 10 & 100 & 92 & 188 \\
\hline Ext 5 & 100 & 92 & 168 \\
\hline
\end{tabular}

*Legenda: Infl: estímulo inflamatório; Ext 10: Extrato na concentração $10 \mathrm{mg} / \mathrm{mL}$; Ext 5: Extrato na concentração $5 \mathrm{mg} / \mathrm{mL}$.

À citocina IL-8 é fator para DII dadas suas propriedades pró-inflamatórias. A dosagem da IL-8 foi mensurada nos tratamentos que receberam estímulo inflamatório. Os resultados foram expressos em relação a um controle que não recebeu estímulo inflamatório (não se induziu a produção da IL-8). Assim, quanto maior a relação obtida, maior a expressão da citocina IL-8 na monocamada. As células que receberam extrato obtiveram valores de IL-8 menores em comparação com as que foram inflamadas e não tratadas, o que comprova que o extrato foi um modulador anti-inflamatório.

Tabela 2. Dosagem de IL-8.

\begin{tabular}{|l|c|}
\hline Tratamento & IL-8 (em função do controle) \\
\hline Infl + Ext 10 & 3,36 \\
\hline Infl + Ext 5 & 4,58 \\
\hline Infl & 13,18 \\
\hline
\end{tabular}

Para melhor mimetização de uma DII, os mesmos testes foram realizados para co-cultura de células Caco-2, que representam a monocamada de células do epitélio intestinal e macrófagos RAW 264.7, que simulam o sistema imune de defesa. Sob mesmo estímulo inflamatório e com mesmas concentrações de extrato, obtiveram-se os resultados descritos na Tabela 3.

Tabela 3. Percentual TER para co-cultura.

\begin{tabular}{|l|c|c|c|}
\hline \multirow{2}{*}{ Tratamento } & \multicolumn{3}{|c|}{ TER (\%) } \\
\cline { 2 - 4 } & Inicial & $\begin{array}{c}\text { Após 48h de } \\
\text { inflamação }\end{array}$ & $\begin{array}{c}\text { Após 48h de } \\
\text { Extrato }\end{array}$ \\
\hline Infl + Ext 10 & 100 & 47 & 110 \\
\hline Infl+ Ext 5 & 100 & 48 & 71 \\
\hline
\end{tabular}

\section{Conclusões}

Observou-se o potencial terapêutico e preventivo do extrato de Passiflora edulis ao aumentar a integridade da monocamada inflamada e daquela saudável, além de atuar na redução de estímulos pró-inflamatórios.

CAZARIN, C. B. B.; SILVA, J., K.; COLOMEU, T. C.; BATISTA, A. G.; MELETTI, L. M. M.; PASCHOAL, J. A. R.; JUNIOR, S. B.; BRAGA, P. A. C.; REYES, F. G. R.; AUGUSTO, F.; MEIRELLES, L. R.; ZOLLNER, R. L.; JÚNIOR, M. R. M. Intake of Passiflora edulis leaf extract improves antioxidant and anti-inflammatory status in rats with 2,4 , 6trinitrobenzenesulphonic acid induced colitis. Journal of Functional Foods, v. 17, p.575-586, 2015.

PODOLSKY, D. K. The current future understanding of inflammatory bowel disease. Best practice \& research Clinical Gastroenterology, v. 16, n. 6, p. 933-943, 2002. 